\title{
Aplastic anemia in pregnancy: a rare case report
}

\section{Vineet Mishra*, Priyankur Roy, Bhumika Vyas, Rohina Aggarwal, Sumesh Choudhary, Neha Mehta}

\begin{abstract}
Department of Obstetrics and Gynaecology, Institute of Kidney Disease and Research Centre, Ahmedabad, Gujarat,
\end{abstract} India

Received: 23 September 2016

Accepted: 20 October 2016

\section{*Correspondence:}

Dr. Vineet Mishra,

E-mail: vineet.mishra.ikdrc@gmail.com

Copyright: (c) the author(s), publisher and licensee Medip Academy. This is an open-access article distributed under the terms of the Creative Commons Attribution Non-Commercial License, which permits unrestricted non-commercial use, distribution, and reproduction in any medium, provided the original work is properly cited.

\begin{abstract}
Aplastic anemia is a rare disease caused by destruction of pluripotent stem cells in bone marrow. During pregnancy it could be life-threatening for both mother and child. The only causal therapy for aplastic anemia is bone marrow transplantation, which is contraindicated during pregnancy because of potential embryo toxicity. Treatment options are erythrocytes and platelet transfusions and immunosuppressive therapy. A 26-year-old multiparous woman was referred to our hospital with low-grade fever. She had undergone bone marrow biopsy elsewhere, which confirmed the diagnosis of aplastic anemia. Routine laboratory tests at admission showed pancytopenia (hemoglobin $-3.5 \mathrm{gm} / \mathrm{dl}$, total leukocyte count $-400 / \mathrm{cmm}$ and platelet count $-20,000 / \mathrm{cmm})$. She was transfused multiple units of packed cell volume, random donor platelets and single donor platelets. At 31 weeks she went into spontaneous labour and gave birth to a preterm female child who succumbed on 3rd post-natal day. After delivery the blood count of the patient did not recover and she did not respond to medication. In spite optimal supportive treatment, she died on her eighth postnatal day. This potential life-threatening disease has a relatively poor prognosis for the mother and a comparatively good prognosis for the baby. Transfusion during pregnancy is the first choice treatment with recommended hemoglobin levels of more than $8.0 \mathrm{gm} / \mathrm{dl}$ and platelet count of more than $20,000 / \mathrm{cmm}$. Cyclosporine A seems a reasonable alternative therapy with a reported success rate in non-pregnant patients of $70 \%$. Our patient was not treated with immunosuppressive agents as she already had neutropenia with worsening infection.
\end{abstract}

Keywords: Aplastic anemia, Immunosuppressive Therapy, Platelet transfusion, Pregnancy

\section{INTRODUCTION}

Aplastic anemia (AA) is a disorder of hematopoietic stem cells that causes pancytopenia and a hypocellular bone marrow without splenomegaly. Fatigue, recurrent infections, bleeding episodes is usual manifestations depending upon cell lineage affected. Pregnancy with aplastic anemia is difficult to manage and can become life threatening for both mother and fetus. There is paucity of data for management during pregnancy due to rarity of this condition in pregnancy. Treatment options are supportive (packed cell and platelet transfusion), immunosuppressive therapy and allogenic stem cell transplantation. The treatment of choice in non-pregnant young patient is allogenic stem cell transplantation, which is contraindicated during pregnancy. ${ }^{1}$ There is no consensus about the optimal supportive care and treatment regimen during pregnancy.

\section{CASE REPORT}

A 26 year multiparous woman (gravida 3 para 1) was referred to the OPD of Obstetrics and Gynecology, Institute of Kidney Diseases and Research Centre, Ahmedabad, at 7 months amenorrhea with aplastic anemia. She was admitted in a private hospital at 24 weeks of gestation with complaints of fever of 10 days history, severe anemia and thrombocytopenia. There, she 
was transfused with 5 units packed cell volume (PCV) and 1 unit single donor platelet (SDP), but there was no improvement in her hematological status. Hence, she underwent bone marrow biopsy and was diagnosed to be a case of aplastic anemia. She was further referred to us for further management. She had no history of drug, radiation or chemical exposure.

On admission, she had low grade fever of 99 degree $F$. She was fairly built and nourished, and her vital signs were within normal limits. Examination of her abdomen was suggestive of 26-28 weeks gravid uterus and external ballotment was present. Her investigations revealed hemoglobin of $3.5 \mathrm{gm} / \mathrm{dl}$, total leukocyte count of $400 / \mathrm{cmm}$ and her platelet count was $20,000 / \mathrm{cmm}$. Her liver enzymes, coagulation profile and renal function tests were within normal limits.

She was diagnosed as a case of aplastic anemia during pregnancy, and its cause could only be confirmed after delivery. She was monitored serially with complete blood count and her target hemoglobin level was above $8.0 \mathrm{gm} / \mathrm{dl}$ and platelet count of more than $20,000 / \mathrm{cmm}$. After 4 days of admission, she developed cough with expectoration and sputum culture and sensitivity was performed which showed heavy growth of klebsiella pneumonia, which was sensitive to Colistin. She was put on appropriate antibiotic and subsequently she got symptomatic relief. During her stay in the hospital, her investigations were as follows.

Table 1: Various counts of blood test.

\begin{tabular}{|lllllll|}
\hline Hemoglobin (in gm/dl) & 6.6 & 7.2 & 8.6 & 9.4 & 7.1 & 7.2 \\
\hline Total leukocyte count (in cumm) & 1040 & 710 & 1440 & 920 & 900 & 950 \\
\hline Polymorphs (in \%) & 27 & 30 & 30 & 28 & 30 & 08 \\
\hline Platelet count (in cumm) & 1000 & 6000 & 13000 & 5000 & 15000 & 31000 \\
\hline
\end{tabular}

She was transfused with 6 units of packed cell volume (PCV), 24 units of random donor platelets (RDP) and 3 units of single donor platelet (SDP) during her course of hospitalization. She had on and off episodes of mild gingival bleeding and epistaxis and she required only supportive treatment for the same.

At 31 weeks of gestation, she developed spontaneous labour pains and delivered a female child of birth weight $1 \mathrm{~kg}$. Unfortunately, the baby expired on $3^{\text {rd }}$ day of life due to complications of prematurity. The patient had an uneventful post-partum period till the $5^{\text {th }}$ post-natal day when she suddenly started developing fever with abdominal pain. On ultrasound examination changes of acute cholecystitis were noted. Blood culture was sent which grew pseudomonas aeruginosa and was sensitive to Meropenam. She was managed conservatively with injectable antibiotics and IV fluids.

On $8^{\text {th }}$ post-partum day, she developed altered sensorium. She developed severe episodes of epistaxis and hemoptysis. She also developed oliguria. Her blood investigations revealed hemoglobin levels of $5.6 \mathrm{gm} / \mathrm{dl}$, total leukocyte count of 450 /cumm with $7 \%$ polymorphs, platelet count of $1000 /$ cumm, serum creatinine of $3.15 \mathrm{mg} / \mathrm{dl}$. She also had developed dyselectrolaemia (serum sodium levels of $133.5 \mathrm{mEq} / \mathrm{dl}$ and serum potassium levels of $2.94 \mathrm{mEq} / \mathrm{dl}$ ) and DIC (increased FDP and decreased fibrinogen levels). Her condition further worsened and despite optimal supportive treatment with blood products, bleeding tendency could not be stopped. She was intubated and put on mechanical ventilatory support. Owing to her poor renal status, she also underwent hemodialysis. On the $9^{\text {th }}$ post-partum day, she succumbed due to MODS with septicemia and could not be resuscitated.

\section{DISCUSSION}

Aplastic anemia is a misnomer as it is pancytopenia and not just anemia. Rather, bone marrow failure is an appropriate term that describes pancytopenia from a variety of mechanisms. It is unclear whether pregnancy causes aplastic anemia or the association of aplastic anemia and pregnancy is just by chance. ${ }^{2,3}$ They seem to be interrelated, as, either aplastic anemia begins and ends with pregnancy, or if the disease pre-exists, then aplastic anemia either worsens during pregnancy or relapses during future pregnancies. A young female patient, who is desirous of pregnancy may be offered immunosuppressive therapy (antilymphocyte globulin and/or cyclosporin) and receive allogenic bone marrow transplantation if immunosuppressive therapy fails.

In general, treatment for aplastic anemia includes withdrawal from offending drugs, supportive care, and some form of definitive therapy. Bone marrow transplantation (BMT) has been reported to be the most effective treatment, with a 5-year survival of 56-89\%. However, BMT is contraindicated during pregnancy because it requires high-doses of immunosuppressive agents or radiation therapy, which would be toxic to the fetus. Successful outcome with good supportive care and blood transfusion facility has been reported in the literature, but these cases did not have platelet refractoriness and were diagnosed during pregnancy. The 
risks of bleeding and infections are high during pregnancy and mortality in aplastic anemia is more than $20 \%$. Review of literature shows a very high maternal mortality rate $(60 \%))^{4,5}$

The following management options should be practiced in a patient with aplastic anemia during pregnancy for the possibility of a good outcome:

- Termination of pregnancy, if diagnosed in the first trimester.

- Maintain adequate hemoglobin level, i.e., more than $8 \mathrm{~g} / \mathrm{dl}$ and platelet count, i.e., more than 20,000/cmm.

- Avoid platelet transfusion until delivery, if there are no bleeding tendencies.

- Prophylactic platelet transfusion at delivery.

- Prophylactic analgesics and antibiotic coverage during delivery.

- Assisted second stage of labour in cases of vaginal delivery.

- In post-partum period, perineal infection should be avoided.

During pregnancy, supportive therapy with packed cell and platelet transfusions are widely used. The benefits of transfusions to prevent bleeding should be weighed against the risk of developing HLA antibodies (which may discourage her candidacy for stem cell transplant) and hemochromatosis and other side effects. ${ }^{6}$

Although case reports have suggested a promising result with antithymocyte immunoglobulin (ATG) or cyclosporine therapy during pregnancy, there is currently little agreement on the universal use of these therapies. There is limited experience with anti-thymocyte immunoglobin (ATG) and cyclosporine treatment during pregnancy. The role of androgens is not clear, and androgen treatment may cause virilisation of female fetuses. The efficacy of corticosteroids or granulocyte colony-stimulating factor is also equivocal. Overall, current evidence does not favour the routine use of any drug therapy in the treatment of pregnancy-associated aplastic anemia. ${ }^{6}$

Cyclosporine (300 mg/day) and granulocyte macrophage colony-stimulating factor (450 mg intravenous weekly) have been used in severe aplastic anemia after 20 weeks of pregnancy though data regarding their use in pregnancy with aplastic anemia is limited. ${ }^{7}$ However, experience from pregnancy following organ transplant shows that cyclosporine is apparently not teratogenic.
Though it is excreted in milk, fetal growth and development were found to be normal. ${ }^{8}$ Our patient was not treated with immunosuppressive agents as she already had neutropenia with worsening infection.

\section{CONCLUSION}

The most important part of treatment of aplastic anemia is supportive therapy. Supportive therapy in the form of repeated blood and platelet transfusions are given to keep haemoglobin above $8 \mathrm{~g} / \mathrm{dl}$ and platelet count above $20,000 / \mathrm{cmm}$. Unfortunately, our patient presented in a very severe stage of aplastic anemia and died after delivery due to sepsis and DIC, despite providing optimal support during and after pregnancy.

\section{Funding: No funding sources \\ Conflict of interest: None declared \\ Ethical approval: Not required}

\section{REFERENCES}

1. Young NS. Acquired aplastic anemia. Ann Intern Med. 2002;136:534.

2. Oosterkamp HM, Brand A, Kluin-Nelemans JC. Pregnancy and severe aplastic anemia - causal role or coincidence? Br. J. Haematol. 1998;103:315-6.

3. Van-Besien K, Tricot G, Golichowski A. Pregnancy associated aplastic anemia- report of three cases. Eur. J. Haematol. 1991;47:253-6.

4. Aitchison RG, Marsh JC, Hows JM, Russell NH, Gordon Smith EC. Pregnancy associated aplastic anemia: a report of five cases and review of current management. Br. J. Haematol. 1989;73:541-5.

5. Thakral B, Saluja K, Sharma RR, Marwaha N, Malhotra P, Varma N, et al. Successful management of pregnancy-associated severe aplastic anemia. Eur. J. Obstet Gynecol Reprod Biol. 2007;131:244-5.

6. Kwon JY, Lee Y, Shin JC, Lee JW, Rha JG, Kim SP. Supportive management of pregnancy - associated aplastic anemia. Int. J. Gynaecol Obstet. 2006;95:115-20.

7. Choudry VP, Gupta S, Gupta M. Pregnancy associated aplastic anemia - a series of 10 cases with review of literature. Haematology. 2002;7:233-8.

8. Ohba T, Yoshimura T, Araki M. Aplastic anemia in pregnancy: treatment with cyclosporine and granulocyte-colony stimulating factor. Acta Obstet Gynecol Scand. 1999;78:458-9.

Cite this article as: Mishra V, Roy P, Vyas B, Aggarwal R, Choudhary S, Mehta N. Aplastic anemia in pregnancy: a rare case report. Int J Reprod Contracept Obstet Gynecol 2016;5:4506-8. 